\title{
Qualitative Loss of Maize under Different Bag Storage Modes
}

\section{Anuradha Kumari ${ }^{1}$, Vishal Kumar ${ }^{2 *}$, Anupam Amitabh ${ }^{3}$, Amit Kumar ${ }^{3}$, Manish Kumar ${ }^{3}$ and Vinita Kashyap ${ }^{3}$}

${ }^{1}$ College of Technology, G B Pant University of Agricultural and Technology, Pantnagar, Uttrakhand, India

${ }^{2}$ College of Agricultural Engineering, Dr. RCAU, Pusa, Bihar, India

${ }^{3}$ College of Technology and Engineering, MPUAT, Udaipur, Rajasthan, India

*Corresponding author

\section{A B S T R A C T}

Comparative assessment of the qualitative loss of maize grain (12.2\%, w.b.) in different storage bags was made. The storage behavior of freshly harvested and chemically treated

\section{Keywords}

Hermetic, Storage,

Germination,

Degradability, Aflatoxin.

Article Info

Accepted:

04 October 2017

Available Online:

10 December 2017
(Alminium Phospide) maize grain was studied at ambient condition $\left(30 \pm 5{ }^{\circ} \mathrm{C}\right)$ in four different modes, i.e. in hermetic bags (super bags), polyethylene bags, plastic bags and jute bags. Weekly changes in physical properties such as grain moisture content, water activity and colour index and degradability in terms of degree of insect infestation, germination percentage and production of aflatoxin were recorded for 8 months. It was observed that the variation in grain moisture content $(0.245$, w.b), water activity $(0.132)$ and colour index $(0.232)$ was least in the super grain bag while the variations were maximum in case of jute bags $(0.855,0.166$ and 0.426 respectively). The germination percentage was maximum for maize stored in super bags $(82 \%)$ and least for jute bags $(07 \%)$ after 8 months storage period. No visible damage due to pest infestation was observed maize samples stored in super bags. The level of aflatoxin in stored maize in hermetic bags was least and under the acceptable limit i.e. $20 \mathrm{ppb}$ throughout the storage period. However the aflatoxin levels in other storage bags were around 100-150 ppb rendering it unfit for human consumption.

\section{Introduction}

Post-harvest losses (PHL) in India amount to 12 to 16 million metric tons of food grains each year, an amount that the World Bank estimates could feed one-third of India's poor. With $2.85 \%$ of India's geographical area and $8.07 \%$ of population, Bihar is the third most populous state in the country (2001 census). About $80 \%$ of Bihar's population is dependent for its livelihood on agriculture. Bihar is the third largest producer of vegetables; fifth largest producer of fruits and eighth largest producer of grains in India. In spite of high volume of production and a good range of crops, the earnings from farming are poor. Postharvest loss is one of the major problems in the region as it increases food prices and reduces farm income, particularly for smallholder farmers (Directorate of Marketing and Inspection, 2002; Groveret al., 2012; Mukherjec, 1968; Nagpal and Kumar, 2012, Nanda et al., 2012) Maize is the third most important cereal crop in India after rice 
and wheat. It accounts for $\sim 9$ per cent of total food grain production in the country. Maize recorded the highest annual growth rate of 2.5 per cent in the area as well as 5.5 per cent in production during the period 2004-05 to 2013-14 (Prasad, and Kumar, 1990). There has been an increasing trend towards substituting other coarse cereals with maize. However, Maize suffers heavy postharvest losses estimated at 20-30 per cent and storage loss alone takes the major share. In Bihar, farmers store Maize crop in homes, on the field, in the open, jute or polypropylene bags, clay structures and baskets. During storage, quantitative as well as qualitative losses occur due to insects, rodents and micro-organisms (Rondon et al., 2001; (Murdock, 2014)).

Hermetic storage bags are airtight storage bags used worldwide for the prevention of post-harvest storage losses. The intrinsic advantage of the hermetic storage of dry cereal grains lies in the generation-by the aerobic metabolism of insect pests and microorganisms-of an oxygen-depleted and carbon dioxide-enriched inter-granular atmosphere of the storage ecosystem. A hermetic storage bags is a safe, cost-effective storage method that controls insect infestations in addition to preserving the quality of grains, while allowing for pesticidefree, short-term and long-term qualitative and quantitative seed preservation, without refrigeration, maintaining seed vigor and pest control (Murdock, 2014).

Hermetic bags need to be validated for its effectiveness in hermetic storage of food grains under Bihar condition. The present study was undertaken in response to requests by farmers, traders and private seed companies to determine the effectiveness of hermetic bags for storage of maize grain. Hence, a comparative study on storage behavior of Maize in different storage bags was made to assess the qualitative and quantitative loss and to validate the advantages of hermetic super grain bags over the conventional storage bags used in the region.

\section{Materials and Methods}

The storage behavior of freshly harvested and chemically treated (Alminium Phospide) maize grain (Shaktimaan I; $12.2 \%$ w. b.) was studied at ambient condition $\left(30 \pm 5^{\circ} \mathrm{C}\right)$ in four different modes, i.e. in hermetic bags (super bags), polyethylene bags, plastic bags and jute bags.

The variation in ambient storage environment such as temperature and relative humidity of were recorded on a daily basis while weekly changes in physical properties such as grain moisture content, water activity \& colour index and degradability in terms of degree of insect infestation, germination percentage and production of aflatoxin were recorded. The experiment was initiated at Pusa, Samastipur, Bihar on September 18, 2014 and terminated on May 8, 2015.

\section{Measurement of Quality Attributes}

\section{Moisture Content}

The total dry materials or the initial moisture content of sample was determined in accordance with AOAC method (Anonymous, 1990).

\section{Water Activity}

Water activity is defined as the ratio of the vapour pressure of water in a material (p) to the vapour pressure of pure water $\left(\mathrm{p}_{\mathrm{o}}\right)$ at the same temperature. When vapour and temperature equilibrium are obtained, the water activity of the sample is equal to the relative humidity of air surrounding the 
sample in a sealed measurement chamber. Multiplication of water activity by 100 gives the equilibrium relative humidity $(\mathrm{ERH})$ in percent.

$\mathrm{A}_{\mathrm{w}}=\mathrm{p} / \mathrm{p}_{\mathrm{o}}=\mathrm{ERH}(\%) / 100$

Water activity affects the shelf life, safety, texture, flavour, and smell of foods. Water activity may be the most important factor in controlling spoilage. Most bacteria, for example, do not grow at water activities below 0.91 .

\section{Germination percentage}

100 grains of maize were sowed in 8 different petri-dishes containing sand and proper irrigation was provided. After a time of $72 \mathrm{~h}$ germination of grain was counted carefully and germination percentages of 8 respective samples were determined.

Germination

Number of seeds sproutedX100

Total number of seeds taken

\section{Insect -pest damage in stored grain}

At the end of every week of storage period random samples were drawn and each sample was visually rated for damage by insect and pests. Although the storage period was short but some indication was obtained with regard to the damage under 8 different types of storage conditions.

\section{Determination of colour}

The changes in colour of the whey drinks were analyzed using Hunters colourLAB. Three Hunter parameters, namely, $L$ (lightness), $a$ (redness/greenness), and $b$ (yellowness/blueness) were measured and total Colour Index was calculated by formula:

$\mathrm{L}_{\mathrm{a}}=\sqrt{ } \mathrm{L}^{2}+\mathrm{a}^{2}+\mathrm{b}^{2}$

\section{Aflatoxin Analysis (ELISA TEST)}

The test sample and the enzyme-labeled aflatoxin are added to the wells of ELISA plate. If toxin is present in the sample, it will compete with the labeled toxin for binding to the antibody. During washing and addition of substrate, a colour will develop, the intensity of which is proportional to the amount of toxin in the sample.

\section{Results and Discussion}

Marginal increase in moisture content was observed in all the treatments which was due to respiration of grain and the variation in relative humidity of storage environment. It was also seen that the moisture increased initially slowly upto30 days of storage period and then it increased rapidly as relative humidity increases day-by-day. The elevation in water activity with storage period was observed which had similar trend as moisture content (Rondon et al., 2001).

It was observed that the variation in grain moisture content $(0.245$, w.b), water activity $(0.132)$ and colour index (0.232) was least in the super grain bags while the variations were maximum in case of chemically untreated jute bags $(0.855,0.166$ and 0.426 respectively). The least variation in moisture content in hermetic storage bags is due to generation-of the aerobic metabolism of insect pests and microorganisms-of an oxygen-depleted and carbon dioxide-enriched inter-granular atmosphere of the storage ecosystem (Fig 35). The hermetic storage bags showed a safe, cost-effective storage method that controls insect infestations in addition to preserving the quality of grains (Murdock, 2014).

The germination percentage was $82 \%$ at the start of the study which decreased during the later days. Grains stored in hermetic bag kept showed least decrease in germination percentage while maize stored in in jute bags 
had lowest germination percentage during 8 months storage. The germination percentage of maize seed in the hermetic grain bag kept inside the jute bag decreased from $82 \%$ to $70 \%$ while in jute bags it decreased to $7 \%$ (Fig 6).

Fig.1 Flow chart showing the experimental plan

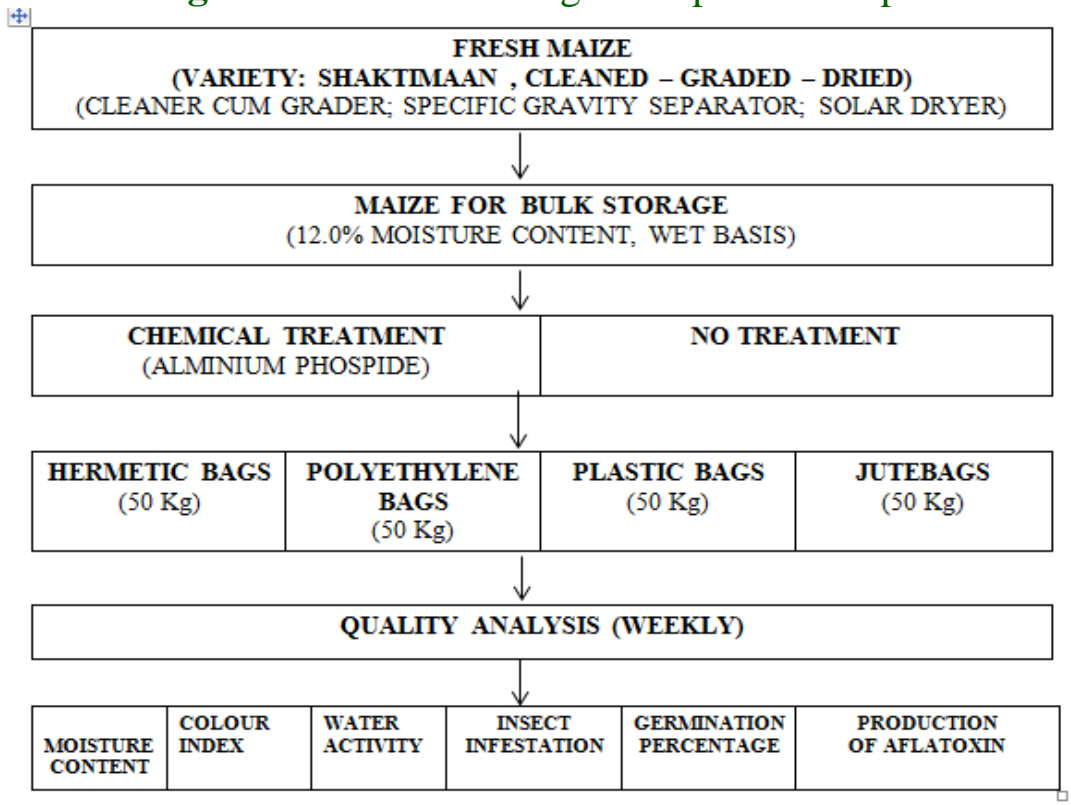

Fig.2 Various treatments under storage study

\begin{tabular}{ll}
\multicolumn{2}{l}{ Treatments } \\
$\mathrm{T}_{1}$ & Hermetic bag + Jute bag \\
$\mathrm{T}_{2}$ & Polyethylene bag + jute bag \\
$\mathrm{T}_{3}$ & Jute bag \\
$\mathrm{T}_{4}$ & Plastic bag \\
$\mathrm{T}_{5}$ & Hermetic bag + Jute bag + Chemical treatment \\
$\mathrm{T}_{6}$ & Polyethylene bag + Jute bag + Chemical treatment \\
$\mathrm{T}_{7}$ & Jute bag + Chemical treatment \\
$\mathrm{T}_{8}$ & Plastic bag + Chemical treatment \\
\hline
\end{tabular}

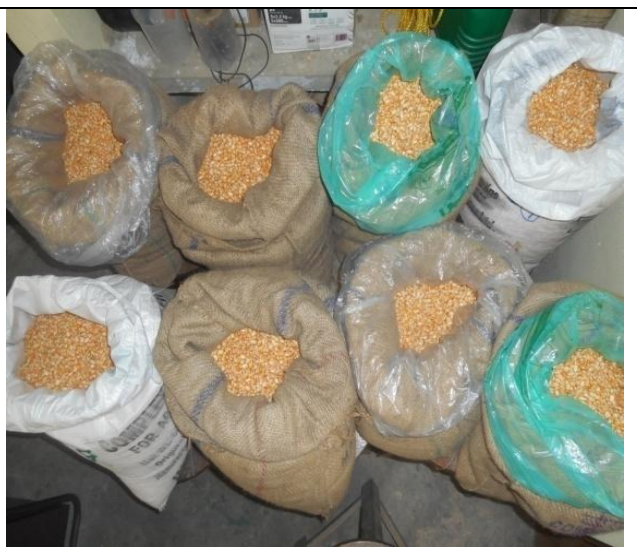

Fig.3 Variation in moisture content during storage of maize

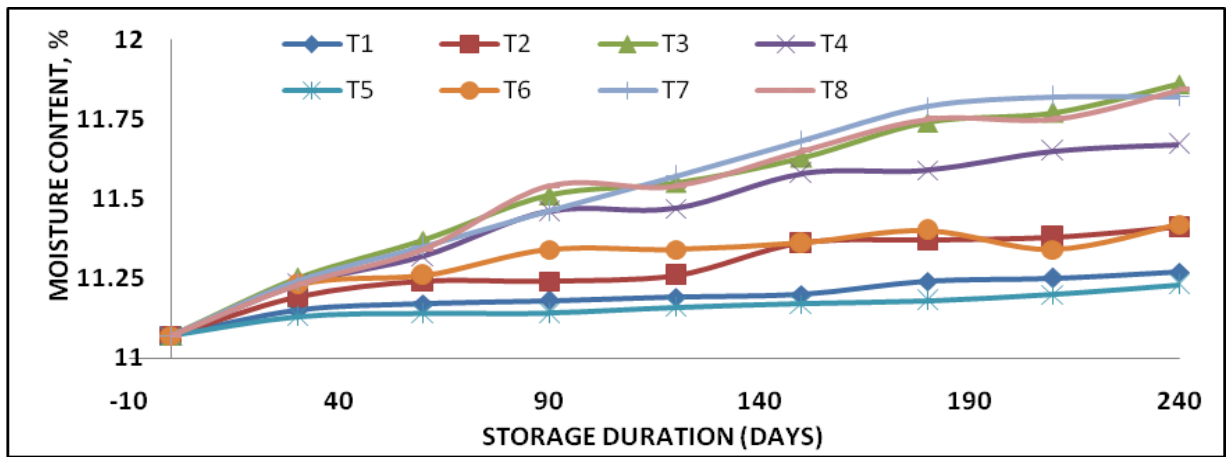


Fig.4 Variation in water activity during storage of maize

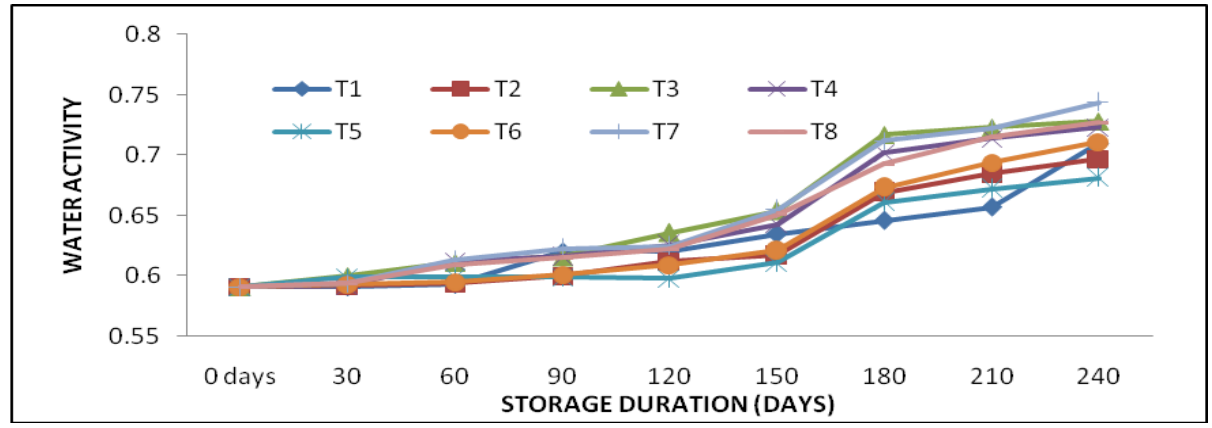

Fig.5 Variation in colour index during storage of maize

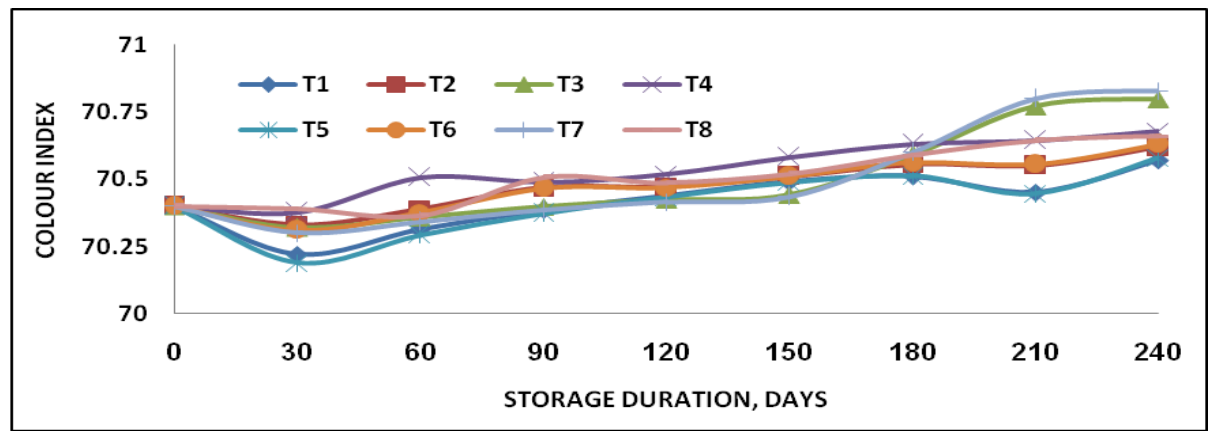

Fig.6 Variation in germination percent during storage of maize

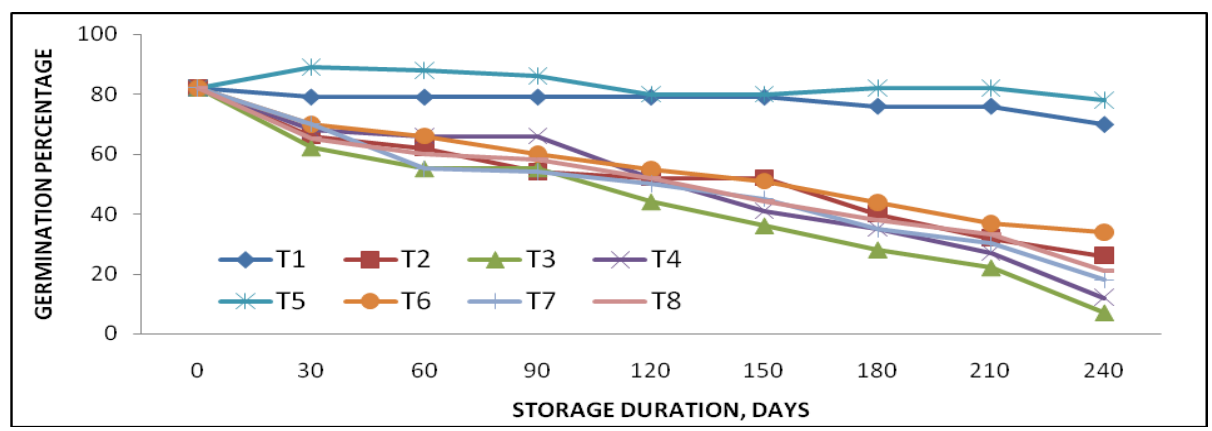

Fig.7 Variation in insect infestation during storage of maize

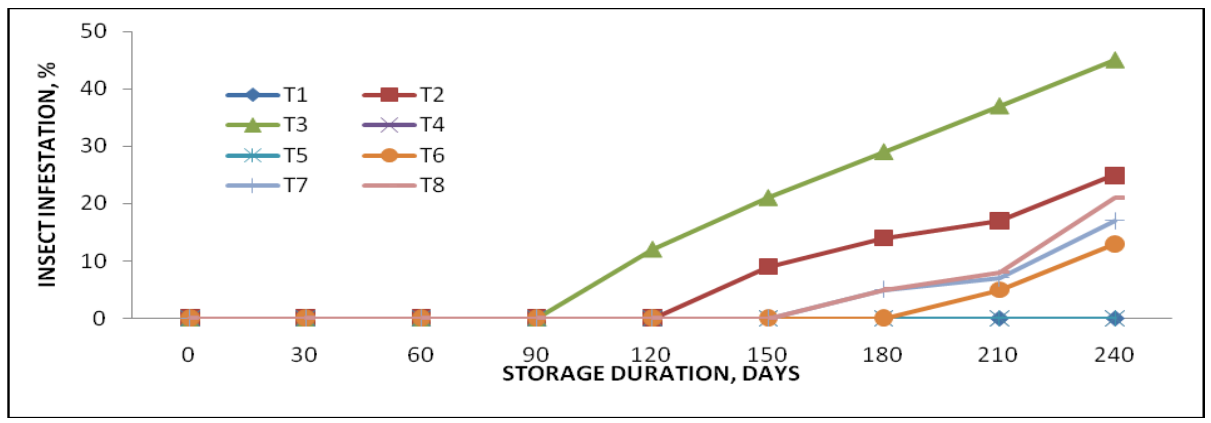


Fig.8 Aflatoxin content observed at 240 days storage period of maize

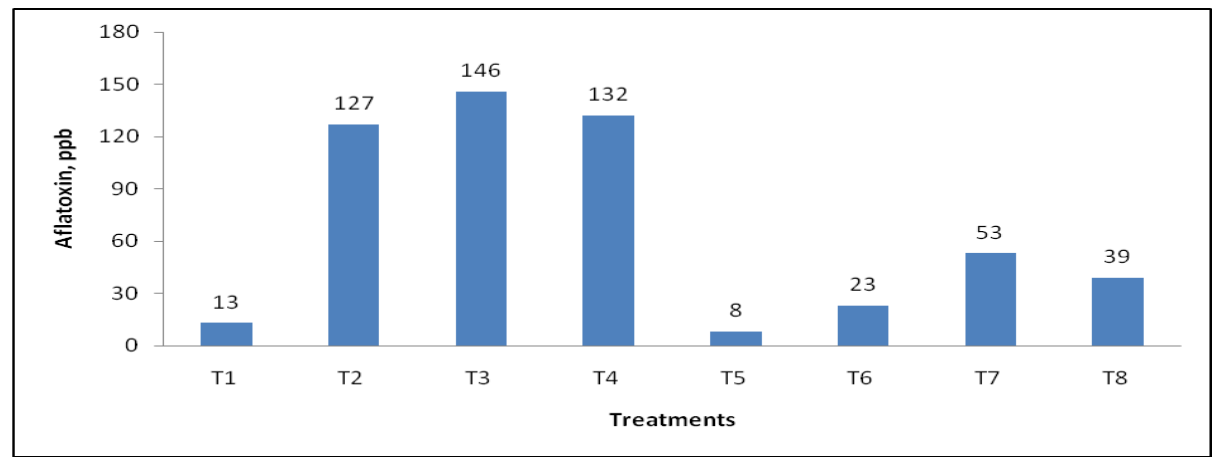

No visible damage due to pest infestation was observed in maize samples stored in super bags (T1 and T5). However, Maize stored in other storages modes was largely infested with weevils which resulted in qualitative and quantative loss (Fig 7). It was seen that the jute bags were heavily infested with insects $(45 \%)$ at the end of 240 days storage period.

The aflatoxin levels under of the stored maize in hermetic bags were least and under the acceptable limit i.e. 20ppb throughout the storage period. However the aflatoxin levels in other storage bags were around 100-150 ppb rendering it unfit for human consumption.

It was concluded that maize could be stored under ambient conditions up to eight months in hermetic storage bag with minimum qualitative and quantitative loss. There is no requirement of any chemical treatment of grains stored in hermetic super bags as the micro environment developed is sufficient enough to restrict the growth of pests, insects and micro-organism. The hermetic bags can be a key post-harvest technology for reducing PHL at storage in the fight against hunger and ensuring food security.

\section{Acknowledgement}

ADMI, UIUC for the financial support for the purchase of hermetic bags from Grainpro. Inc., USA through IRRI under the project
'Assessment and Prevention of Post-Harvest Losses in Wheat \&wheat and Maize in Selected Districts of Bihar'.

\section{References}

Directorate of Marketing and Inspection, Nagpur. (2002). Report of the survey of marketable surplus and post-harvest losses of food grains in India (199799).Department of Agriculture and Cooperation, Government of India, New Delhi.

Grover, D. K., Singh, Jasdev, and Singh, Satwinder (2012). Assessment of marketable and marketed surplus of major foodgrains in Punjab. AERC study no. 32. Agro-economic Reserach Center, Department of Economics and sociology, Punjab Agricultural University, Ludhiana.

Mukherjec, P.B.; Jotwani, M.G.; SircarP.;and Yadav T.D. (1968). Studies on the incidence and extent of damage due to insect pests in stored seeds.Indian Journal of Entomology. 30(1): 61-65.

Murdock, L.L.; Baribusta, D. and DeBoer, J. L. (2014). Hermetic Storage of Grain in Developing Nations. Journal of stored products research, 58: 1-2.

Nagpal, M and Kumar, A. (2012). Grain losses in India and government policies. Quality assurance and safety of Crops and Food, 4(3):143. 
Nanda, S. K.; Vishwakarma, R. K.; Bathla, H. V. L.; Rai, A. and Chandra, P. (2012). Harvest and post-harvest losses of major crops and livestock produce in India. A report published by All India Coordinated Research Project on PostHarvest Technology (ICAR).

Prabhakar, B. S.; and Mukherjee R. K. (1977). Effect of storage conditions on viability of rice seeds. The Harvestor, 19: 4-6.
Prasad, S., and Kumar, R. (1990). Design, development and testing a low cost storage bin for grain crops.

Rondon, J. N., Sassaki R. M., L. Zaidan B. P., and Felippe G. M. (2001). Effects of moisture content and temperature during storage on germination of the achenes of Bidensgarddneri baker. Revtabrasil. Bot., Sao Paulo, 24 (1): 3541.

\section{How to cite this article:}

Anuradha Kumari, Vishal Kumar, Anupam Amitabh, Amit Kumar, Manish Kumar and Vinita Kashyap. 2017. Qualitative Loss of Maize under Different Bag Storage Modes. Int.J.Curr.Microbiol.App.Sci. 6(12): 177-183. doi: https://doi.org/10.20546/ijcmas.2017.612.023 